Editorial

\title{
What Value is there in Assessing Postmenopausal Women for Vitamin D Deficiency?
}

\section{Qual o valor da avaliação de deficiência de vitamina $D$ em mulheres na pós-menopausa?}

\author{
Mariana Lima Mascarenhas Moreira ${ }^{1}$ Francisco José Albuquerque de Paula ${ }^{1}$ \\ ${ }^{1}$ Faculdade de Medicina de Ribeirão Preto, Universidade de São Paulo, \\ Ribeirão Presto, SP, Brazil
}

Rev Bras Ginecol Obstet 2017;39:585-586.

Vitamin D is included, along with thyroid and steroid hormones, within the unique category of endocrine molecules that act through nuclear receptors. Differently from its partners, until recently vitamin $D$ was thought to be a specialized hormone with an action limited to the control of mineral and bone metabolism. ${ }^{1}$ The misconception has been recently reviewed after the recognition that the vitamin $D$ receptor (VDR) as well as the cell machinery to synthesize the active hormone $1,25(\mathrm{OH})_{2} \mathrm{D}$ are largely distributed among most tissues and cells. Therefore, vitamin D can potentially modulate an ample diversity of systems and functions, including the cardiovascular system, energy metabolism, immune modulation and cell proliferation. ${ }^{2}$ The new knowledge reinvigorated the interest to unveil the ideal levels of vitamin D to obtain osteomineral, as well as non-mineral health.

The biochemical measurement of 25 -hydroxivitamin D (25$\mathrm{OHD}$ ) is considered the best surrogate parameter to assess the status of vitamin D sufficiency. Until 2010, the cut-off point for 25-OHD serum levels was set at $15 \mathrm{ng} / \mathrm{mL}$, and it was an uncommon laboratory parameter, seldom requested by a specialist. Since then, a passionate discussion emerged regarding one key point: what are the ideal serum levels of 25-OHD? Some authors have stated that they are the serum levels that are able to promote the intestinal absorption of calcium, stabilize parathyroid (PTH) serum levels and enable porper bone mineralization. However, this point is still a conundrum.

In a perfect world, the new knowledge would stimulate clinical investigation through long prospective studies, as well as randomized double-blinded studies to establish the ideal levels of vitamin D. Conversely, a new proposal was made based on previously published studies, most small and observational investigations, and the ideal serum levels of 25-OHD were set at $30 \mathrm{ng} / \mathrm{mL}^{3}$ Curiously, most healthy individuals (70\%), indepen- dently of age, sex and country, do not have 25-OHD serum levels above $30 \mathrm{ng} / \mathrm{mL}$. A different position was held by the Institute of Medicine (IOM), ${ }^{4}$ which estimated that $20 \mathrm{ng} / \mathrm{mL}$ were the appropriate levels. The passionate debate about vitamin $\mathrm{D}$ deficiency went beyond the realm of science and migrated to the lay media, and patients are currently pressuring physicians to know their vitamin D status, with the hope of preventing diseases simply by taking vitamin D supplementation. ${ }^{5}$ The discussion about the appropriate levels of vitamin $\mathrm{D}$ goes beyond the focus of the present editorial. Recently published and ongoing well-designed studies aiming at evaluating the effect of vitamin D supplementation on the prevention of diseases will give appropriate scientific support to the query about the role of vitamin D on health maintenance. For instance, in a recent study, vitamin D supplementation (3,750 IU versus $600 \mathrm{IU} /$ day during 1 year) did not ameliorate insulin resistance in overweight individuals. ${ }^{6}$ Moreover, The Vitamin D Assessment Study, a randomized, double-blinded, placebo-controlled trial followed-up 5,108 individuals for 3 years, and oral vitamin D3 at an initial dose of 200,000 IU, followed a month later by monthly doses of $100,000 \mathrm{IU}$, were administered to half of the sample. The authors concluded that a monthly high-dose of vitamin $D$ supplementation does not prevent cardiovascular disease. ${ }^{7}$ Another arm of the same study observed that the highdose vitamin $\mathrm{D}_{3}$ supplementation of 100.000 IU monthly over 2.5-4.2 years did not prevent falls or fractures in a healthy, ambulatory care, adult population. ${ }^{8}$ Soon, other vitamin D randomized, double-blinded, placebo-controlled trials will be available, and they will provide appropriate scientific support for the potential of vitamin $D$ to prevent different disorders and about the ideal serum levels of 25-OHD.

Another important point related to this subject is the target population to be evaluated in the vitamin D measurement. ${ }^{9}$
Address for correspondence Francisco José Albuquerque de Paula, Prof, MD, Faculdade de Medicina de Ribeirão Preto, Universidade de São Paulo, Av. Bandeirantes 3900, 14049-900, Ribeirão Preto, SP, Brasil (e-mail: fjpaula@fmrp.usp.br).
DOI https://doi.org/ 10.1055/s-0037-1606858. ISSN 0100-7203.
Copyright $\odot 2017$ by Thieme Revinter Publicações Ltda, Rio de Janeiro, Brazil

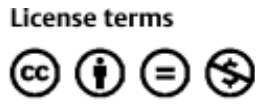


Regarding this issue, there is a consensus among medical associations that there is no need to screen the general population routinely. ${ }^{3,4,9}$ The US Prevention Service Task Force (USPSTF) issued a recommendation that the current evidence for screening for vitamin D deficiency in community-dwelling, non-pregnant, asymptomatic adults $\geq 18$ years of age to improve health outcomes is insufficient. Moreover, the USPSTF stated that the balance between the benefits and harms of screening and early intervention cannot be determined. ${ }^{10}$ The American Congress of Obstetricians and Gynecologists, the American Geriatric Society, and the National Osteoporosis Foundation recommend testing for vitamin D as part of osteoporosis management or to prevent falls. The Endocrine Society ${ }^{3}$ and the Brazilian Society of Endocrinology and Metabolism ${ }^{11}$ recommend the screening of vitamin D status only among patients at risk. However, they defined a large list of conditions as risks for vitamin D deficiency: a) patients with osteoporosis or other bone-health problems, like rickets, primary hyperparathyroidism and osteomalacia; b) those with malabsorption syndromes, such as celiac disease, cystic fibrosis, Chron disease and bariatric surgery; c) those who take medications that interfere in vitamin D metabolism (anticonvulsants, glucocorticoids, antifungals, antiretrovirals, cholestyramine and orlistat, for example); and d) older adults with history of falls and/or nontraumatic fractures. The other risk groups listed in these recommendations are rather controversial. ${ }^{11}$ For example, obesity and darker skin pigmentation are associated with low levels of total serum 25-OHD, but it is not clear whether these factors reflect vitamin D deficiency or increased risk of adverse clinical outcomes. No reasonable explanation was provided in relation to the paradoxical concurring vitamin D deficiency with an increase in bone mass in African-Americans as well as in obese individuals. It is unnecessary to observe that the aforementioned list will soon have to be revised and most likely shortened.

Therefore, not only the reference values of vitamin $D$ have to be thoroughly scrutinized, but the population at risk for hypovitaminosis $\mathrm{D}$ has to be better defined. There is a consensus that it is not necessary to screen the general population routinely. In the same line, there is no scientific support to link vitamin D with benefits in non-mineral outcomes such as in the cases of diabetes mellitus, cancer and death. Moreover, it is necessary to call attention to the fact that no medical association or institu- tion has labeled menopause as a clinical risk for vitamin D deficiency.

Conflicts of Interest

The authors have no conflicts of interest to disclose.

\section{References}

1 de Paula FJ, Rosen CJ. Vitamin D safety and requirements. Arch Biochem Biophys 2012;523(01):64-72. Doi: 10.1016/j.abb.2011.12.002

2 Scientific Advisory Committee on Nutrition. Vitamin D and health. London, UK: SACN; 2016

3 Holick MF, Binkley NC, Bischoff-Ferrari HA, et al; Endocrine Society. Evaluation, treatment, and prevention of vitamin D deficiency: an Endocrine Society clinical practice guideline. J Clin Endocrinol Metab 2011;96(07):1911-1930. Doi: 10.1210/jc.2011-0385

4 Institute of Medicine. Dietary reference intakes: calcium and vitamin D. Washington, DC: National Academies Press; 2011

5 Manson JE, Brannon PM, Rosen CJ, Taylor CL. Vitamin D deficiency Is there really a pandemic? N Engl J Med 2016;375(19):1817-1820. Doi: 10.1056/NEJMp1608005

6 Mousa A, Naderpoor N, de Courten MP, et al. Vitamin D supplementation has no effect on insulin sensitivity or secretion in vitamin D-deficient, overweight or obese adults: a randomized placebocontrolled trial. Am J Clin Nutr 2017;105(06):1372-1381. Doi: 10.3945/ajcn.117.152736

7 Scragg R, Stewart AW, Waayer D, et al. Effect of monthly high-dose vitamin D supplementation on cardiovascular disease in the vitamin D assessment study: a randomized clinical trial. JAMA Cardiol 2017;2(06):608-616. Doi: 10.1001/jamacardio.2017.0175

8 Khaw KT, Stewart AW, Waayer D, et al. Effect of monthly high-dose vitamin D supplementation on falls and non-vertebral fractures: secondary and post-hoc outcomes from the randomised, doubleblind, placebo-controlled ViDA trial. Lancet Diabetes Endocrinol 2017;5(06):438-447. Doi: 10.1016/S2213-8587(17)30103-1

9 Rosen CJ, Abrams SA, Aloia JF, et al. IOM committee members respond to Endocrine Society vitamin D guideline. J Clin Endocrinol Metab 2012;97(04):1146-1152. Doi: 10.1210/jc.2011-2218

10 LeFevre ML; U.S. Preventive Services Task Force. Screening for vitamin D deficiency in adults: U.S. Preventive Services Task Force recommendation statement. Ann Intern Med 2015;162(02): 133-140. Doi: 10.7326/M14-2450

11 Maeda SS, Borba VZ, Camargo MB, et al; Brazilian Society of Endocrinology and Metabology (SBEM). Recommendations of the Brazilian Society of Endocrinology and Metabology (SBEM) for the diagnosis and treatment of hypovitaminosis D. Arq Bras Endocrinol Metabol 2014;58(05):411-433. Doi: 10.1590/0004-2730000003388 